\title{
A Derivative Spectrometric Method for Hydroquinone Determination in the Presence of Kojic Acid, Glycolic Acid, and Ascorbic Acid
}

\author{
Zenovia Moldovan, Dana Elena Popa, Iulia Gabriela David, \\ Mihaela Buleandra, and Irinel Adriana Badea \\ Department of Analytical Chemistry, Faculty of Chemistry, University of Bucharest, 4-12 Regina Elisabeta Av., \\ District 3, 030018 Bucharest, Romania
}

Correspondence should be addressed to Dana Elena Popa; dana_lena1978@yahoo.com

Received 22 September 2016; Accepted 14 December 2016; Published 18 January 2017

Academic Editor: Jose S. Camara

\begin{abstract}
Copyright ( $) 2017$ Zenovia Moldovan et al. This is an open access article distributed under the Creative Commons Attribution License, which permits unrestricted use, distribution, and reproduction in any medium, provided the original work is properly cited.

A new, simple, and sensitive spectrometric method was developed for hydroquinone (HQ) determination in the presence of other depigmenting agents (kojic acid (KA), glycolic acid (GA), and ascorbic acid (AA)), commonly introduced in skin lightening products. The method is based on the oxidation of the depigmenting agents by potassium dichromate in sulfuric acid medium and subsequent measurement of the amplitude of the first-order derivative absorption spectrum at $268 \mathrm{~nm}$. By applying the zerocrossing method, at this wavelength, the oxidation products of $\mathrm{KA}, \mathrm{AA}$, and GA do not interfere in the indirect determination of HQ. Beer's law was obeyed in the range of $0.22-22 \mu \mathrm{g} \cdot \mathrm{mL}^{-1} \mathrm{HQ}$, with a detection limit of $0.07 \mu \mathrm{g} \cdot \mathrm{mL}^{-1}$. The developed method was applied with good results for the first time to the rapid determination of HQ in binary, ternary, and quaternary mixtures, thus proving that it could represent an effective tool for various skin lightening products analyses.
\end{abstract}

\section{Introduction}

Human skin contains melanocytes (cells located at the base of the epidermis), which produce melanin (a dark macromolecular vital pigment) by a combination of enzymatically catalyzed chemical reactions. This process is named melanogenesis and it intensifies after exposure to UVB radiation, causing the skin to visibly tan. The aim of the melanogenesis is to protect the hypodermis from the DNA photodamage. The first step consists of tyrosine oxidation to dopaquinone catalyzed by tyrosinase [1]. The abnormal accumulation of melanin induces melasma, a chronic skin disorder that results in brownish facial pigmentation. Taking into account that tyrosinase is the enzyme responsible for the melanin synthesis tyrosinase inhibitors are used as whitening or antihyperpigment agents due to their ability to suppress dermalmelanin production [2].

Hydroquinone (HQ) is considered to be one of the strongest inhibitors of melanin production and for more than 25 years it has been established as the most effective ingredient for treating melasma [3]. However, its long-term application has numerous adverse effects, including irritative dermatitis, melanocyte destruction, contact dermatitis, and ochronosis. Matsumoto et al. [4] published recently a study related to the risk of systemic effects of HQ when using skin lightening cosmetics containing it. The adverse effects of HQ are transitory below the $3.0 \%$ level (2\% HQ is the maximum concentration permitted by the United States Food and Drug Administration (USFDA), whereas $4.0 \%$ HQ formulations are only available by prescription [5]). Concentrations of HQ above $5.0 \%$ could cause local irritation [6] and even persistent hypopigmentation named leukoderma [7]. Therefore, over the past years HQ has become a controversial skin-care agent for topical use. It should be mentioned that the whitening products containing HQ have been banned in many countries because of concerns related to cancer risk [8]. However, in order to minimize the risk of side effects, many clinical studies reported partial or total replacement of HQ in various cosmetics. The medical literature data also report that combination therapy is more effective than single agent use 
[9]. As a result, a series of dermatological creams contain binary, ternary, or quaternary mixtures of $\mathrm{HQ}$ and other tyrosinase inhibitors such as glycolic acid (GA), kojic acid (KA), and ascorbic acid (AA). The addition of this last one, which is a well-known antioxidant, enhances the stability of $\mathrm{HQ}$ as it can be easily oxidized (even in a tube) and become ineffective [10].

Taking into consideration both benefits and risks of using HQ-containing cosmetics, the quantitative determination of the HQ level in bleaching creams is imperative. For this purpose, many studies on HQ determination in different cosmetics are reported. The employed analytical methods are based on the specific properties of HQ exploited by chromatographic (HPLC [11-14]), capillary electrochromatographic [15], voltammetric [16-19], and spectrometric techniques [20-31]. The advantages of the spectrometric techniques consist in the fact that they use accessible and simpler equipment, have shorter analysis time, and are cheaper than the chromatographic techniques. The use of UV-Vis spectrometry has enhanced rapidly over the last few years. Some of the advantages of these methods are precision, short analysis time, and less reagents consumption [20]. The spectrometric determinations of HQ in cosmetic products were based on direct measurement of UV absorbance of HQ [21, 22], UV derivative spectrometry [23], spectrometric ratio difference method [24], the successive ratio subtraction coupled with constant multiplication UV spectrometry [25], fluorescence spectroscopy [26], or the absorbance measurement of the product resulting in a redox reaction between HQ and specific reagents. For instance, trace levels of HQ were determined by UV absorption measurements after its oxidation to $\mathrm{p}$-benzoquinone (BQ) by oxygen in the presence of ammonium meta-vanadate as an oxidizing catalyst [27]. The catalytic oxidation of $\mathrm{HQ}$ to $\mathrm{BQ}$ by $\mathrm{KMnO}_{4}$ in alkaline medium was also used for the spectrometric determination of HQ [28]. Ammonium molybdate (Mo(VI)) was used to oxidize $\mathrm{HQ}$ in acidic medium and the resulting molybdenum (V) was spectrometrically monitorized [29]. The inhibitory effect of $\mathrm{HQ}$ on the oxidation of an organic reagent (Rhodamine B) was used for HQ determination by a kinetic spectrometric method [30]. UV spectrometric investigations of the HQ polymerization in the presence of $\mathrm{Cr}(\mathrm{VI})$ were also recently reported [31].

In the present work a simple, accurate, and precise firstorder derivative spectrometric method was proposed for the first time to quantify $\mathrm{HQ}$ in the presence of other depigmenting agents, namely, KA, GA, and AA, commonly present in cosmetic products. The method is based on the oxidation of $\mathrm{HQ}$ by $\mathrm{K}_{2} \mathrm{Cr}_{2} \mathrm{O}_{7}$ in sulfuric acid medium and subsequent absorbance measurement of the first-order derivative spectrum of the oxidation product (BQ) at $268 \mathrm{~nm}$.

\section{Materials and Methods}

2.1. Chemicals. All chemicals were of analytical reagent grade and were purchased from Sigma-Aldrich. Deionized-distilled water was used throughout the experiments.

Aqueous stock solutions of $\mathrm{HQ}, \mathrm{KA}, \mathrm{GA}$, and $\mathrm{AA}$ $\left(10^{-2} \mathrm{~mol} \cdot \mathrm{L}^{-1}\right)$ were freshly prepared and used to obtain the working standard solutions. When not used, the solutions were stored in the refrigerator. A $5 \mathrm{~mol} \cdot \mathrm{L}^{-1} \mathrm{H}_{2} \mathrm{SO}_{4}$ solution was obtained by diluting concentrated sulfuric acid $(98 \%$, $\left.1.84 \mathrm{~g} \cdot \mathrm{mL}^{-1}\right)$. Working solutions of $10^{-3}$ and $5 \times 10^{-3} \mathrm{~mol} \cdot \mathrm{L}^{-1}$ $\mathrm{K}_{2} \mathrm{Cr}_{2} \mathrm{O}_{7}$ resulted after dilution of a $10^{-1} \mathrm{~mol} \cdot \mathrm{L}^{-1} \mathrm{~K}_{2} \mathrm{Cr}_{2} \mathrm{O}_{7}$ stock solution. Eppendorf vary-pipettes (10-100; 100-1000; and $500-2500 \mu \mathrm{L}$ ) were employed to deliver accurate volumes.

2.1.1. Depigmenting Agents in Acid Medium. An aliquot $(1 \mathrm{~mL})$ of $10^{-3} \mathrm{~mol} \cdot \mathrm{L}^{-1}$ solution of $\mathrm{HQ}, \mathrm{AA}, \mathrm{KA}$, or GA was transferred into a $5 \mathrm{~mL}$ volumetric flask. After adding $5 \mathrm{~mol} \cdot \mathrm{L}^{-1} \mathrm{H}_{2} \mathrm{SO}_{4}(1 \mathrm{~mL})$, the mixture was brought to the mark with distilled water and homogenized. Then, the absorbance spectrum was recorded against water as reference. The derivative spectra were plotted with a $2 \mathrm{~nm}$ interval from the zeroorder spectra of the individual analyzed solutions.

\subsubsection{Mixtures of Depigmenting Agents and Potassium Dichro-} mate in Acid Medium. An aliquot $(1 \mathrm{~mL})$ of $10^{-3} \mathrm{~mol} \cdot \mathrm{L}^{-1}$ solution of $\mathrm{HQ}, \mathrm{KA}, \mathrm{GA}$, or AA, $1 \mathrm{~mL}$ of $5 \mathrm{~mol} \cdot \mathrm{L}^{-1} \mathrm{H}_{2} \mathrm{SO}_{4}$, and a known volume of $10^{-3}$ or $5 \times 10^{-3} \mathrm{~mol} \cdot \mathrm{L}^{-1} \mathrm{~K}_{2} \mathrm{Cr}_{2} \mathrm{O}_{7}$ (added in small excess, to obtain a weak yellow colored solution) were transferred into a $5 \mathrm{~mL}$ volumetric flask and diluted to the mark. For each solution the absorption spectrum was recorded in the range $215-400 \mathrm{~nm}$, against water as reference. This was necessary due to the fact that between 325 and $400 \mathrm{~nm}$ only $\mathrm{K}_{2} \mathrm{Cr}_{2} \mathrm{O}_{7}$ is absorbed, thus being mandatory the removal of the $\mathrm{K}_{2} \mathrm{Cr}_{2} \mathrm{O}_{7}$ excess influence. For each mixture, a corresponding blank solution was prepared by transferring into a $5 \mathrm{~mL}$ calibrated flask $1 \mathrm{~mL}$ of $5 \mathrm{~mol} \cdot \mathrm{L}^{-1} \mathrm{H}_{2} \mathrm{SO}_{4}$ and a known volume of $10^{-3}$ or $5 \times 10^{-3} \mathrm{~mol} \cdot \mathrm{L}^{-1} \mathrm{~K}_{2} \mathrm{Cr}_{2} \mathrm{O}_{7}$ to obtain a final aqueous solution having the concentration equal to that of the unreacted $\mathrm{K}_{2} \mathrm{Cr}_{2} \mathrm{O}_{7}$ (deduced from its absorbance at $350 \mathrm{~nm}$; see the details given in Section 3.1.). The spectrum of the analyte oxidation product was obtained by subtracting the blank spectrum from the spectrum recorded for the analyte in the presence of a small excess of the oxidant $\left(\mathrm{K}_{2} \mathrm{Cr}_{2} \mathrm{O}_{7}\right)$.

Binary, ternary, and quaternary mixtures of $\mathrm{HQ}$ and other dermatological active agents (KA, GA, and $\mathrm{AA}$ ) in acidic medium and in the presence of $\mathrm{K}_{2} \mathrm{Cr}_{2} \mathrm{O}_{7}$ were prepared in the same manner as the individual depigmenting agents. The differences between absorbencies of the mixtures and the corresponding blank solutions were also obtained.

2.2. Apparatus. Absorbance measurements were performed in the 215-400 nm wavelength range on a UV-VIS spectrometer (V-530 Jasco-Japan), with fully integrated PC running Spectra Manager software, equipped with quartz cells of $1.00 \mathrm{~cm}$. Suitable settings were slit width $1 \mathrm{~cm}$ and scan speed $100 \mathrm{~nm} \cdot \mathrm{min}^{-1}$.

\section{Results and Discussions}

3.1. Zero- and First-Order Derivative UV Spectrometric Studies. $\mathrm{HQ}, \mathrm{KA}, \mathrm{GA}$, and AA absorb UV radiation having char- 


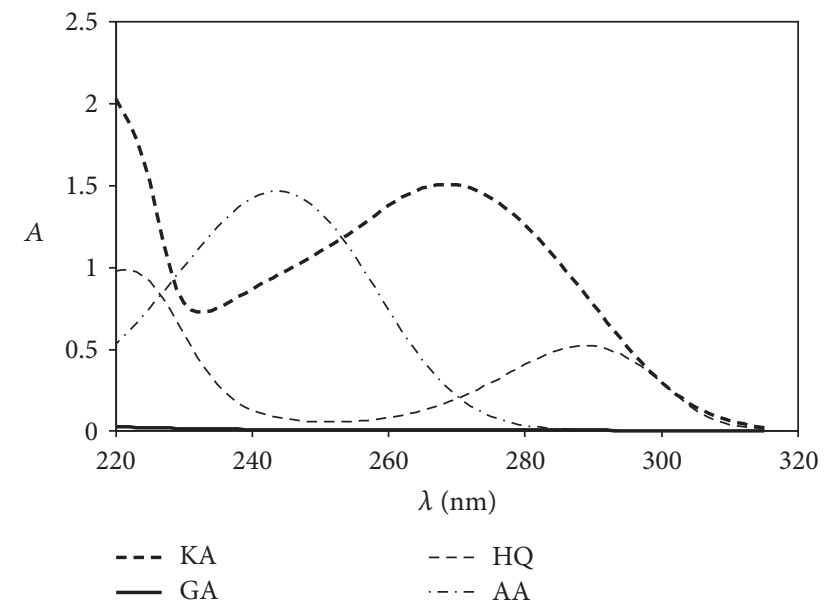

FIGURE 1: UV absorption spectra of HQ, KA, AA, and GA; every compound has the same concentration $\left(2 \times 10^{-4} \mathrm{~mol} \cdot \mathrm{L}^{-1}\right)$.

acteristic absorption spectra (Figure 1). As it can be observed, the spectra of HQ and KA overlap significantly. Moreover, in the given experimental conditions, the calculated molar absorptivity $\left(\varepsilon_{\mathrm{HQ}}=2600 \mathrm{~L} \cdot \mathrm{mol}^{-1} \cdot \mathrm{cm}^{-1}\right.$ at $\left.\lambda_{\text {max }, \mathrm{HQ}}=289 \mathrm{~nm}\right)$ of HQ is smaller than that of AA $\left(\varepsilon_{\mathrm{AA}}=7350 \mathrm{~L} \cdot \mathrm{mol}^{-1} \cdot \mathrm{cm}^{-1}\right.$ at $\left.\lambda_{\text {max }, \mathrm{AA}}=244 \mathrm{~nm}\right)$ and of $\mathrm{KA}\left(\varepsilon_{\mathrm{KA}}=7500 \mathrm{~L} \cdot \mathrm{mol}^{-1} \cdot \mathrm{cm}^{-1}\right.$ at $\lambda_{\max , \mathrm{KA}}=269 \mathrm{~nm}$ ).

By applying the zero-crossing method, the first- and second-order derivative spectra of $\mathrm{HQ}, \mathrm{KA}$, and AA do not permit the determination of HQ in ternary mixtures due to the fact that there is no wavelength where only HQ presents a measurable signal (Figures 2(a) and 2(b)).

It was observed that HQ presents an analytical signal at $303 \mathrm{~nm}$ in its third-order derivative spectrum, while the same order derivative spectra of the other tested compounds intersect the abscissa (Figure 2(c)). However, the analytical signal of HQ is very small, even at a concentration of $2 \times 10^{-4} \mathrm{~mol} \cdot \mathrm{L}^{-1}\left(22 \mu \mathrm{g} \cdot \mathrm{mL}^{-1}\right)$, which leads to a very low sensitivity.

Under these circumstances, a new methodology was established. This one considers the capacity to be oxidized of the above-mentioned compounds when $\mathrm{K}_{2} \mathrm{Cr}_{2} \mathrm{O}_{7}$ in acidic medium is used as oxidizing agent. Thus, another series of UV spectra were recorded for the individual active compounds in the presence of $\mathrm{K}_{2} \mathrm{Cr}_{2} \mathrm{O}_{7}$ in sulfuric acid medium. As depicted in Figure 3 the oxidation product of $\mathrm{HQ}$ in presence of the $\mathrm{K}_{2} \mathrm{Cr}_{2} \mathrm{O}_{7}$ excess (spectrum (1)) exhibits an absorption band in the same wavelength region $(325-400 \mathrm{~nm})$ as the $\mathrm{K}_{2} \mathrm{Cr}_{2} \mathrm{O}_{7}$ solution (spectrum (2)). It must be mentioned that the UV absorption spectrum of BQ (not shown) presents a characteristic absorption band in the range $225-250 \mathrm{~nm}$ similar to the spectrum of the $\mathrm{HQ}$ oxidation product resulting from the reaction of HQ with $\mathrm{K}_{2} \mathrm{Cr}_{2} \mathrm{O}_{7}$ in sulfuric acid medium (spectrum (2)). In order to obtain only the spectrum of the HQ oxidation product (spectrum (3)), the spectral subtraction of spectrum (2) from spectrum (1) was performed. Each analyzed mixture was prepared in the presence of a known $\mathrm{K}_{2} \mathrm{Cr}_{2} \mathrm{O}_{7}$ excess.
The concentration of the unreacted $\mathrm{K}_{2} \mathrm{Cr}_{2} \mathrm{O}_{7}$ was deduced from the absorbance of the mixture at $350 \mathrm{~nm}$, where only dichromate ion is absorbed. To achieve this aim a calibration curve was accomplished using $\mathrm{K}_{2} \mathrm{Cr}_{2} \mathrm{O}_{7}$ solutions with different concentrations $\left(2 \times 10^{-5}-2 \times 10^{-4} \mathrm{~mol} \cdot \mathrm{L}^{-1}\right)$ in $1 \mathrm{~mol} \cdot \mathrm{L}^{-1} \mathrm{H}_{2} \mathrm{SO}_{4}$. Using the equation of the regression line $\left(A_{350 \mathrm{~nm}}=0.4875 c-0.0002 ; R^{2}=0.9994 ; c\right.$ is the dichromate concentration) the blank concentration (having the same absorbance at $350 \mathrm{~nm}$ as the mixture of the analytes in presence of dichromate excess) is calculated.

The UV spectra of the investigated compounds in the absence and in the presence of $\mathrm{K}_{2} \mathrm{Cr}_{2} \mathrm{O}_{7}$ differ significantly in the case of HQ and AA (Figure 4), whereas for KA only a small decrease of the absorption band intensity is observed in the presence of $\mathrm{K}_{2} \mathrm{Cr}_{2} \mathrm{O}_{7}$ in sulfuric acid medium, suggesting that $\mathrm{KA}$ is not oxidized in these conditions.

The redox reactions between HQ, GA [32], AA [33], and $\mathrm{K}_{2} \mathrm{Cr}_{2} \mathrm{O}_{7}$ in sulfuric acid medium are shown in Scheme 1.

By overlaying the spectra of the reaction products of $\mathrm{HQ}, \mathrm{KA}, \mathrm{GA}, \mathrm{AA}$, and $\mathrm{K}_{2} \mathrm{Cr}_{2} \mathrm{O}_{7}$, the first one cannot be determined in presence of the others (Figure 5(a)). Although at the first sight one may consider that $\mathrm{HQ}$ can be determined in the presence of $\mathrm{GA}$ and $\mathrm{AA}$, it must be mentioned that in real samples the GA and AA concentrations are even five times higher than the HQ concentration, their contribution becoming significant.

Applying the first-order derivative, the analytical signal attributed to the oxidation product of HQ (benzoquinone (BQ)) could be used for the indirect determination of HQ in the presence of the other ingredients, at the zero-crossing of KA oxidation product $(268 \mathrm{~nm})$, where the amplitudes of the first-order derivative spectra of AA and GA oxidation products are also zero (Figure 5(b)).

3.2. Optimization of the Working Parameters. In order to optimize the working conditions of the proposed method, the influence of the sulfuric acid concentration at constant HQ and dichromate contents was studied. It was observed that the analytical signal increases with increasing the concentration of $\mathrm{H}_{2} \mathrm{SO}_{4}$ up to $1 \mathrm{~mol} \cdot \mathrm{L}^{-1}$; then it remains almost constant. Further experiments were made on samples prepared in $1 \mathrm{~mol} \cdot \mathrm{L}^{-1} \mathrm{H}_{2} \mathrm{SO}_{4}$. The stability of the reaction product between HQ and dichromate was monitored by spectrometry in the time range $0-1800 \mathrm{sec}$. The measurements made at $240 \mathrm{~nm}$ (the wavelength corresponding to the maximum absorbance of the HQ oxidation product in the presence of dichromate) indicated that the absorbance was stable within the tested period.

\subsection{Analytical Parameters of the Indirect Spectrometric} Method Developed for HQ Quantitative Determination. Using the above optimized spectrophotometric method developed for the indirect determination of HQ (via its oxidation in the presence of dichromate) a linear relationship was obtained between $\mathrm{d} A / \mathrm{d} \lambda$ (at $268 \mathrm{~nm}$ ) and the HQ concentration. The parameters of the calibration curve, obtained by linear square regression of the results, are given in Table 1 . 


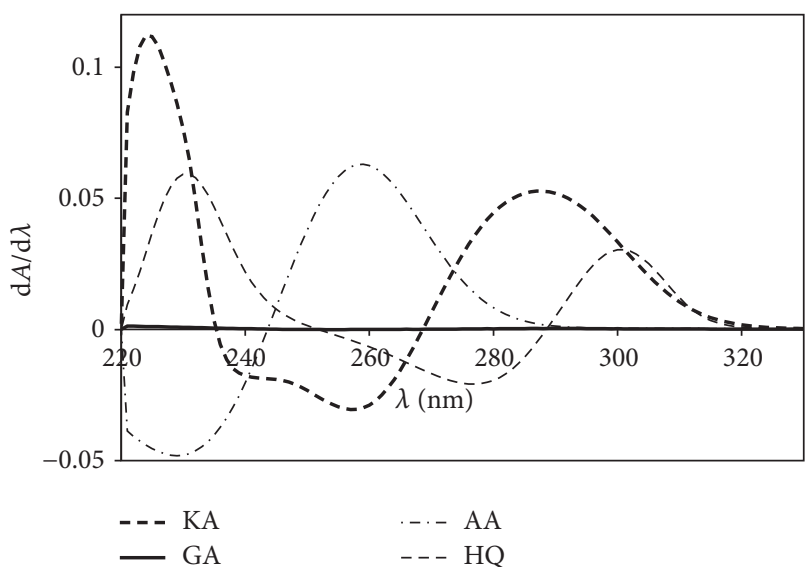

(a)

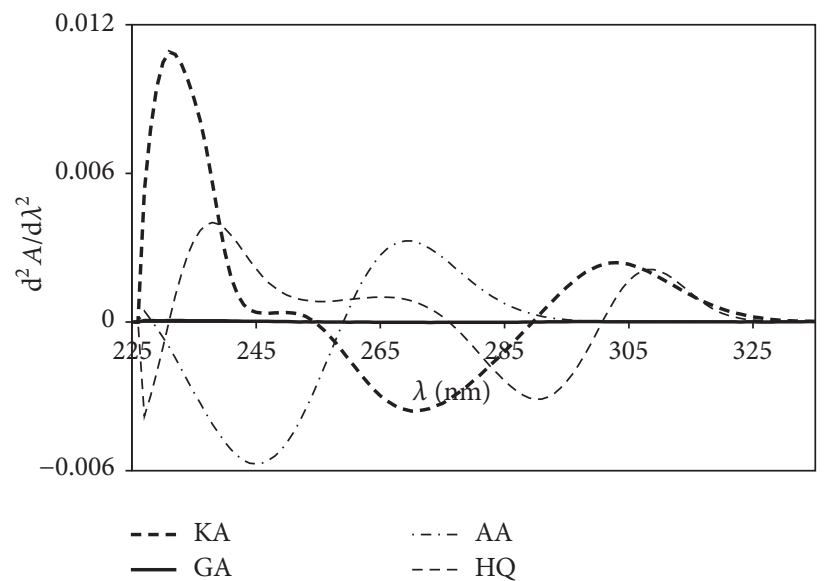

(b)

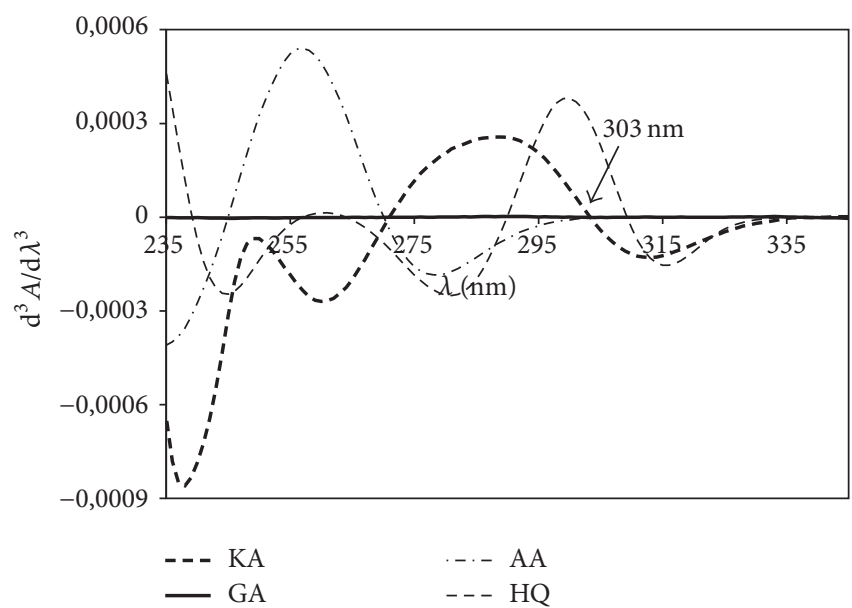

(c)

FIGURE 2: (a) First-order, (b) second-order, and (c) third-order derivative spectra of HQ, KA, AA, and GA; every compound has the same concentration $\left(2 \times 10^{-4} \mathrm{~mol} \cdot \mathrm{L}^{-1}\right)$.

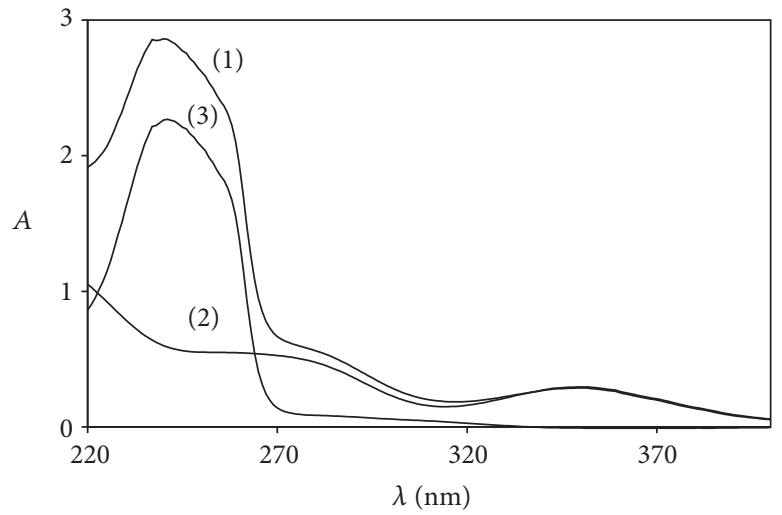

FIGURE 3: UV spectra of (1) $2 \times 10^{-4} \mathrm{~mol} \cdot \mathrm{L}^{-1} \mathrm{HQ}$ in the presence of $2 \times 10^{-4} \mathrm{~mol} \cdot \mathrm{L}^{-1} \mathrm{~K}_{2} \mathrm{Cr}_{2} \mathrm{O}_{7}$ (in excess), in $1 \mathrm{~mol} \cdot \mathrm{L}^{-1}$ sulfuric acid; (2) $\mathrm{K}_{2} \mathrm{Cr}_{2} \mathrm{O}_{7}$ at a level of concentration corresponding to those unreacted in solution (1); (3) = (1) - (2).

The limit of quantification (LOQ) was determined by the analysis of samples with known concentration of HQ and by establishing the minimum level at which the analyte can be quantified with acceptable accuracy and precision. The limit of detection (LOD) was considered as the signal to noise ratio of $3: 1$ [34].

A comparison with other reported methods shows that the proposed spectrometric method is more sensitive, with 


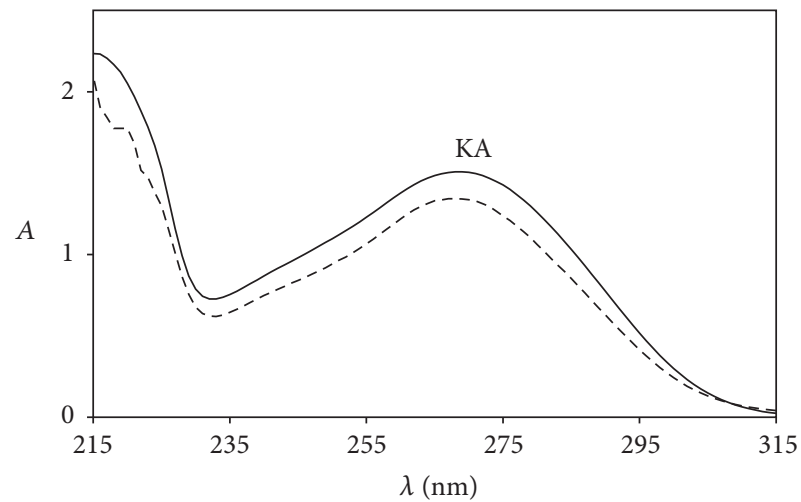

(a)

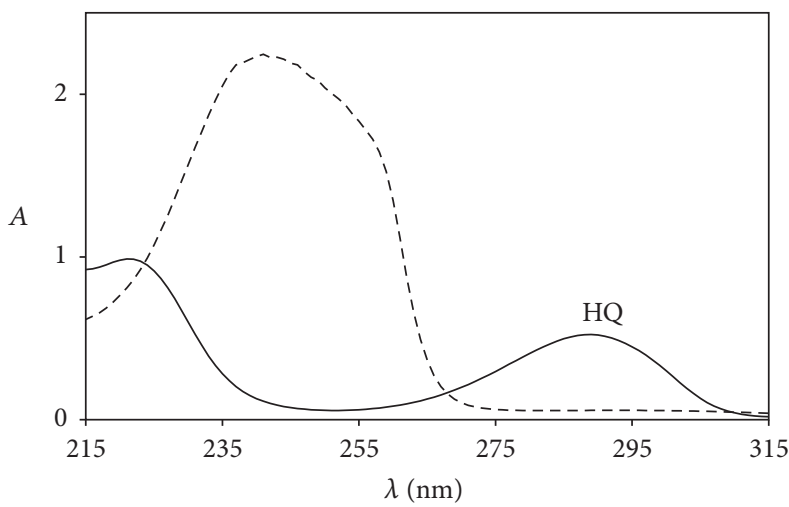

(c)

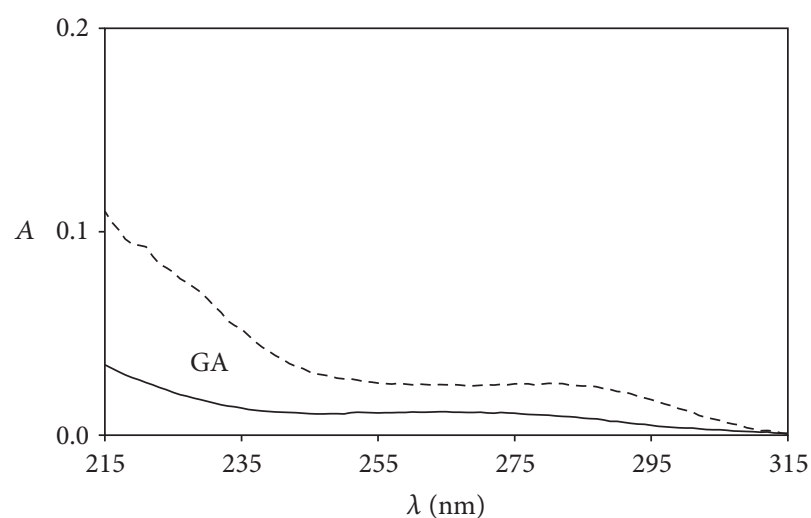

(b)

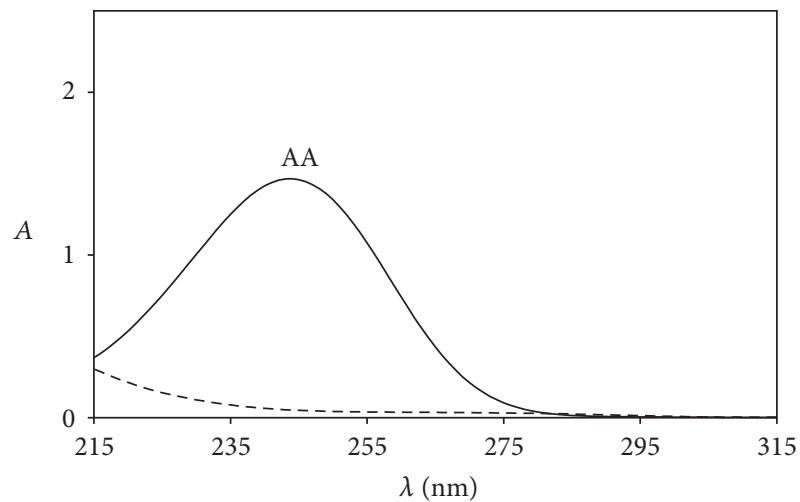

(d)

Figure 4: Overlaid spectra of the studied compounds in the absence (solid lines) and in the presence (dashed line) of $\mathrm{K}_{2} \mathrm{Cr}_{2} \mathrm{O}_{7}$ in $1 \mathrm{~mol}^{-1} \mathrm{~L}^{-1}$ sulfuric acid; every compound has the same concentration $\left(2 \times 10^{-4} \mathrm{~mol} \cdot \mathrm{L}^{-1}\right)$.

TABLE 1: Analytical parameters of the first-order derivative spectrometric method for the indirect HQ determination.

\begin{tabular}{lc}
\hline Parameter & Value \\
\hline Linear range, $\mu \mathrm{g} \cdot \mathrm{mL}^{-1}$ & $0.22-22$ \\
Intercept, $a$ & 0.0018 \\
Intercept standard deviation, $s_{a}$ & 0.00032 \\
Slope, $b$ & 0.0031 \\
Slope standard deviation, $s_{b}$ & 0.00003 \\
Determination coefficient, $R^{2}$ & 0.9994 \\
LOD, $\mu \mathrm{g} \cdot \mathrm{mL}^{-1}$ & 0.07 \\
LOQ, $\mu \mathrm{g} \cdot \mathrm{mL}^{-1}$ & 0.22 \\
\hline
\end{tabular}

a larger linear range of $0.22-22 \mu \mathrm{g} \cdot \mathrm{mL}^{-1}$. At the same time, the proposed method is less time consuming, no heating is required, and it is eco-friendly (no use of organic solvents) and inexpensive (Table 2).

3.4. Precision and Accuracy. The precision and the accuracy of the proposed spectrometric method were obtained using solutions containing HQ at three different concentration levels, within the established linear range. The results presented in Table 3 show high accuracy (estimated by the percent recovery $(R \%)$, between $99.39 \%$ and $100.15 \%$ ) and precision (estimated by the means of relative standard deviation (RSD\%), between $1.34 \%$ and $2.60 \%$ ) of the obtained results.

The obtained percent recovery values lie within the accepted limits for these concentration levels [35].

\subsection{Application of the Developed Method to the Determina-} tion of HQ in Binary, Ternary, and Quaternary Mixtures. The literature data report various combinations of different topical agents for melasma treatment [36]. Hydroquinone is generally the main component of the formulations [10]. It is usually combined with glycolic acid, kojic acid, and ascorbic acid resulting in binary ( $4 \% \mathrm{HQ}+2 \% \mathrm{GA} ; 4 \% \mathrm{HQ}+10 \% \mathrm{GA}$; $2 \% \mathrm{HQ}+2 \% \mathrm{KA})[37,38],(4 \% \mathrm{HQ}+10 \% \mathrm{AA})[39]$; ternary $(2 \% \mathrm{HQ}+10 \% \mathrm{GA}+2-4 \% \mathrm{KA})[40],(4 \% \mathrm{HQ}+2.5 \% \mathrm{AA}+$ $0.75 \% \mathrm{KA})[41]$; or quaternary (2\% HQ + GA + KA + AA) [42] mixtures.

As it can be seen, the four ingredients are found in the dermatological formulations in variable mixtures and concentrations ( $\mathrm{HQ} \leq 4 \%$; $\mathrm{AA} \leq 10 \%$; $\mathrm{KA} \leq 2 \%$; $\mathrm{GA} \leq$ $10 \%)$. In order to determine how the possible interfering compounds affect the HQ quantitation, binary mixtures were prepared, the concentration of the other active compounds 


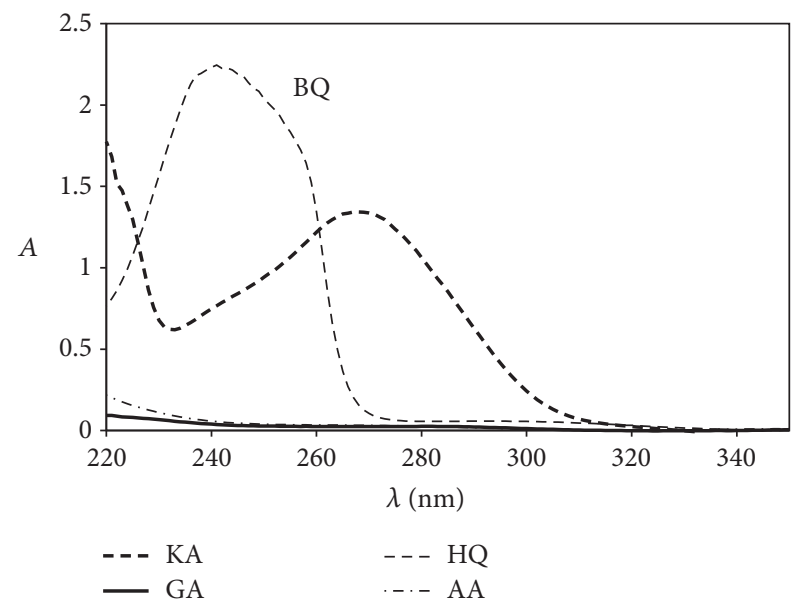

(a)

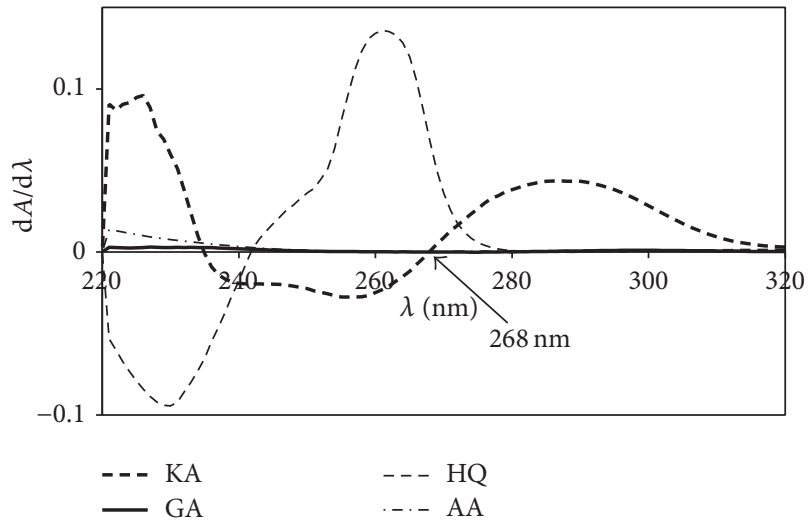

(b)

Figure 5: Overlaid (a) zero-order and (b) first-order derivative spectra of HQ, KA, GA, and AA in the presence of $\mathrm{K}_{2} \mathrm{Cr}_{2} \mathrm{O}_{7}$ in $1 \mathrm{~mol}^{-1}$ sulfuric acid; every compound has the same concentration $\left(2 \times 10^{-4} \mathrm{~mol} \cdot \mathrm{L}^{-1}\right)$.

TABLE 2: Comparison of the proposed method with the reported spectrometric methods for HQ determination.

\begin{tabular}{lccc}
\hline Analytical signal/working conditions & Linear range, $\mu \mathrm{g} \cdot \mathrm{mL}^{-1}$ & Application \\
\hline$A_{302 \mathrm{~nm}} / \mathrm{HQ}$ in $\mathrm{H}_{2} \mathrm{SO}_{4}$ & $2-12$ & Body lotions \\
$A_{293 \mathrm{~nm}} / \mathrm{HQ}$ in methanolic solution & $10-50$ & Cosmetic creams \\
$A_{293 \mathrm{~nm}} / \mathrm{HQ}+\mathrm{O}_{2}+\mathrm{NH}_{4} \mathrm{VO}_{3}$ in 2-propanol : water & $0.025-2$ & Cosmetic creams \\
$1: 1$ & & $10-26$ & Cosmetic creams \\
$\mathrm{d} A / \mathrm{d} \lambda_{302 \mathrm{~nm}} / \mathrm{HQ}$ in $\mathrm{H}_{2} \mathrm{SO}_{4}$ & $10-100$ & Skin whitening \\
$A_{580 \mathrm{~nm}} / \mathrm{HQ}+\left(\mathrm{NH}_{4}\right)_{2} \mathrm{MoO}_{4}+10 \% \mathrm{H}_{2} \mathrm{SO}_{4} ;$ & & formulations \\
20 -minute reaction time, $100^{\circ} \mathrm{C}$ & $1-26$ & Pharmaceuticals \\
$A_{610 \mathrm{~nm}} / \mathrm{HQ}+\mathrm{KMnO}_{4}$ in alkaline medium; & & [23] \\
$30-35-$ minute reaction time & & Synthetic mixtures \\
$\mathrm{d} A / \mathrm{d} \lambda_{302} \mathrm{~nm} / \mathrm{HQ}$ in the presence of $\mathrm{KA}, \mathrm{AA}$, and & $0.22-22$ & [28] \\
$\mathrm{GA}+\mathrm{K}_{2} \mathrm{Cr} \mathrm{O}_{7}$ in $\mathrm{H}_{2} \mathrm{SO}_{4}$, instantaneous reaction; & & Present work \\
room temperature & &
\end{tabular}

being smaller than, equal to, and higher than the HQ concentration.

The recipes of the dermatological formulations that contain all the four active ingredients do not contain information about the KA, GA, and AA concentrations. Therefore, in the present study, the ternary mixtures contain all the four components at the lowest concentration level (percent ratio, $\mathrm{HQ}: \mathrm{KA}: \mathrm{GA}: \mathrm{AA}=1: 1: 1: 1)$ and at the highest accepted concentration level (percent ratio, HQ:KA:GA:AA = $2: 1: 5: 5)$.

The determination of HQ in combination with the mentioned active ingredients was studied by applying the proposed indirect derivative spectrometric method. Different combinations of HQ and the other depigmenting compounds and the analytical results for HQ determination are given in Tables 4 and 5 . The percent recovery values $(R \%)$ summarized in Table 3 are very close to $100 \%$ (between 99.20 and $101.60 \%$ ), a fact that reveals the accuracy of the proposed method in the determination of HQ in binary mixtures.
TABLE 3: The precision and accuracy of the results obtained by the proposed spectrometric method; $n$-number of independent measurements; $n=5$; SD: standard deviation.

\begin{tabular}{lccc}
\hline \multicolumn{2}{c}{$\mathrm{HQ}, \mu \mathrm{g} \cdot \mathrm{mL}^{-1}$} & $\mathrm{RSD}, \%$ & $R, \%$ \\
Considered & Found $\pm \mathrm{SD}$ & & \\
\hline 2.2 & $2.19 \pm 0.05$ & 2.31 & 99.39 \\
5.5 & $5.51 \pm 0.07$ & 1.34 & 100.15 \\
11 & $10.99 \pm 0.29$ & 2.60 & 99.88 \\
\hline
\end{tabular}

In the case of ternary and quaternary mixtures, HQ can be determined by the proposed spectrometric method with good recovery values, the standard deviations supporting also the fact that the results are reliable and comparable.

All the experimental data obtained during this study led to the results presented throughout this paper and these revealed that the developed spectrometric method is a useful 


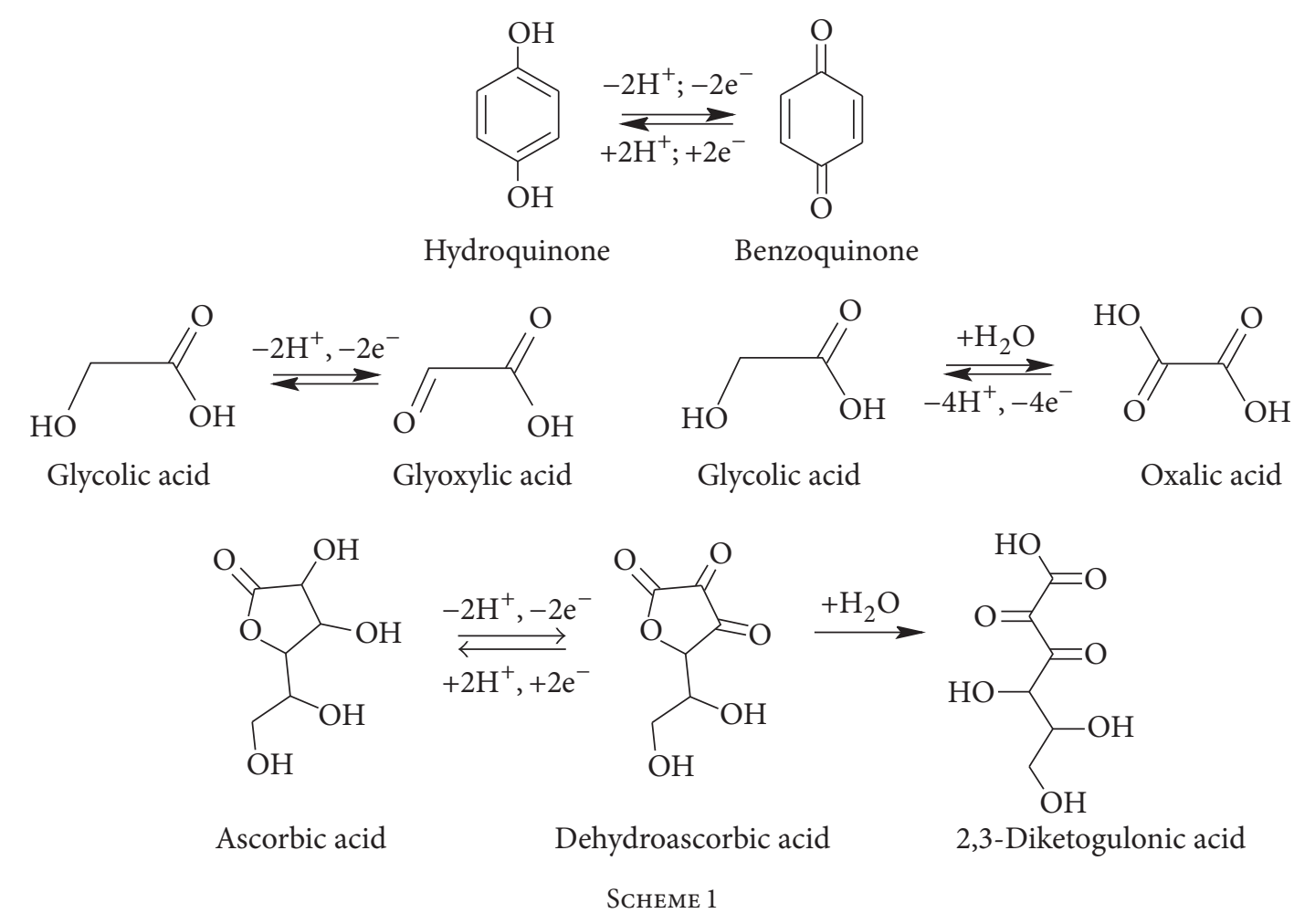

TABLE 4: Results of the HQ determination in synthetic binary mixtures by applying the proposed spectrometric method; $n=3$.

\begin{tabular}{|c|c|c|c|c|}
\hline \multirow{2}{*}{ Mixtures } & \multirow{2}{*}{ Percent ratio, HQ: KA/AA/GA } & \multicolumn{2}{|c|}{ HQ concentration, $\mu \mathrm{g} \cdot \mathrm{mL}^{-1}$} & \multirow{2}{*}{$R \%$} \\
\hline & & Considered & Found \pm SD & \\
\hline \multirow{5}{*}{$\mathrm{HQ}+\mathrm{KA}$} & $4: 1$ & 4 & $4.04 \pm 0.08$ & 101.06 \\
\hline & $2: 1$ & 4 & $4.04 \pm 0.05$ & 101.06 \\
\hline & $1: 1$ & 4 & $4.06 \pm 0.07$ & 101.33 \\
\hline & $1: 1.5$ & 4 & $3.96 \pm 0.05$ & 99.47 \\
\hline & $1: 2$ & 4 & $3.97 \pm 0.04$ & 99.20 \\
\hline \multirow{5}{*}{$\mathrm{HQ}+\mathrm{AA}$} & $2: 1$ & 4 & $3.99 \pm 0.06$ & 99.73 \\
\hline & $1: 1$ & 4 & $3.98 \pm 0.05$ & 99.47 \\
\hline & $1: 2$ & 4 & $4.02 \pm 0.04$ & 100.53 \\
\hline & $1: 2.5$ & 4 & $4.00 \pm 0.06$ & 100.00 \\
\hline & $1: 5$ & 4 & $4.04 \pm 0.07$ & 101.06 \\
\hline \multirow{5}{*}{$\mathrm{HQ}+\mathrm{GA}$} & $1: 1$ & 4 & $4.04 \pm 0.05$ & 101.06 \\
\hline & $1: 2$ & 4 & $4.05 \pm 0.06$ & 101.17 \\
\hline & $1: 3$ & 4 & $4.03 \pm 0.07$ & 100.80 \\
\hline & $1: 4$ & 4 & $4.02 \pm 0.06$ & 100.53 \\
\hline & $1: 5$ & 4 & $4.06 \pm 0.08$ & 101.60 \\
\hline
\end{tabular}

analytical tool for HQ quantitation in the presence of GA, KA, and AA from real samples containing varied mixtures of the mentioned compounds.

\section{Conclusions}

The new proposed method for the hydroquinone determination in the presence of other dermatologic active ingredients (kojic acid, ascorbic acid, and glycolic acid) is cheap and simple, and it is not time consuming. The used reaction system contains an oxidant $\left(\mathrm{K}_{2} \mathrm{Cr}_{2} \mathrm{O}_{7}\right)$ that does not necessitate any additional steps. Moreover, the method does not contain variables which influence the reliability of the results. The accuracy, the precision, and the results obtained analyzing the synthetic mixtures recommend the spectrometric procedure for skin depigmenting products analysis and control by means of hydroquinone level monitoring, in binary, ternary, or quaternary mixtures with kojic acid, glycolic acid, and ascorbic acid. The application of the spectrometric method 
TABLE 5: Results of the HQ determination in ternary and quaternary synthetic mixtures by applying the proposed spectrometric method; $n=3$.

\begin{tabular}{|c|c|c|c|}
\hline \multirow{2}{*}{$\begin{array}{l}\text { Percent ratio, } \\
\text { HQ: GA : KA : AA }\end{array}$} & \multicolumn{2}{|c|}{ HQ concentration, $\mu \mathrm{g} \cdot \mathrm{mL}^{-1}$} & \multirow{2}{*}{$R \%$} \\
\hline & Considered & Found $\pm \mathrm{SD}$ & \\
\hline $1: 5: 1: 0$ & 2 & $1.85 \pm 0.08$ & 92.55 \\
\hline $1: 5: 2: 0$ & 2 & $1.87 \pm 0.06$ & 93.62 \\
\hline $4: 0.75: 0: 2.5$ & 8 & $8.34 \pm 0.35$ & 104.26 \\
\hline $1: 1: 1: 1$ & 2 & $1.83 \pm 0.05$ & 91.49 \\
\hline $2: 5: 1: 5$ & 4 & $4.19 \pm 0.05$ & 104.79 \\
\hline
\end{tabular}

on synthetic mixtures represents the first step for further researches on real samples.

\section{Competing Interests}

The authors declare that they have no competing interests.

\section{References}

[1] R. Uchida, S. Ishikawa, and H. Tomoda, "Inhibition of tyrosinase activity and melanine pigmentation by 2-hydroxytyrosol," Acta Pharmaceutica Sinica B, vol. 4, no. 2, pp. 141-145, 2014.

[2] V. M. Sheth and A. G. Pandya, "Melasma: a comprehensive update: part I," Journal of the American Academy of Dermatology, vol. 65, no. 4, pp. 689-697, 2011.

[3] N. C. Dlova, S. H. Hamed, J. Tsoka-Gwegweni, and A. Grobler, "Skin lightening practices: an epidemiological study of South African women of African and Indian ancestries," British Journal of Dermatology, vol. 173, no. 2, pp. 2-9, 2015.

[4] M. Matsumoto, H. Todo, T. Akiyama et al., "Risk assessment of skin lightening cosmetics containing hydroquinone," Regulatory Toxicology and Pharmacology, vol. 81, pp. 128-135, 2016.

[5] United States Food and Drug Administration, Hydroquinone studies under the National Toxicology Program (NTP), 2010, http://www.fda.gov/AboutFDA/CentersOffices/ OfficeofMedicalProductsandTobacco/CDER/ucm203112.htm.

[6] P. L. García, M. I. R. M. Santoro, A. K. Singh, and E. R. M. Kedor-Hackmann, "Determination of optimum wavelength and derivative order in spectrophotometry for quantitation of hydroquinone in creams," Revista Brasileira de Ciencias Farmaceuticas/Brazilian Journal of Pharmaceutical Sciences, vol. 43, no. 3, pp. 397-404, 2007.

[7] Y.-H. Lin, Y.-H. Yang, and S.-M. Wu, "Experimental design and capillary electrophoresis for simultaneous analysis of arbutin, kojic acid and hydroquinone in cosmetics," Journal of Pharmaceutical and Biomedical Analysis, vol. 44, no. 1, pp. 279-282, 2007.

[8] M. M. C. G. Peters, T. W. Jones, T. J. Monks, and S. S. Lau, "Cytotoxicity and cell-proliferation induced by the nephrocarcinogen hydroquinone and its nephrotoxic metabolite 2,3,5(tris-glutathion-S-yl)hydroquinone," Carcinogenesis, vol. 18, no. 12, pp. 2393-2401, 1997.

[9] M. Rendon, M. Berneburg, I. Arellano, and M. Picardo, "Treatment of melasma," Journal of the American Academy of Dermatology, vol. 54, no. 5, pp. S272-S281, 2006.
[10] A. D. Katsambas and A. J. Stratigos, "Depigmenting and bleaching agents: coping with hyperpigmentation," Clinics in Dermatology, vol. 19, no. 4, pp. 483-488, 2001.

[11] S. Siddique, Z. Parveen, Z. Ali, and M. Zaheer, "Qualitative and quantitative estimation of hydroquinone in skin whitening cosmetics," Journal of Cosmetics, Dermatological Sciences and Applications, vol. 2, no. 3, pp. 224-228, 2012.

[12] D. Amponsah, R. Voegborlo, and G. E. Sebiawu, "Determination of amount of hydroquinone in some selected skinlightening creams sold in the Ghanaian market," International Journal of Scientific \& Engineering Research, vol. 5, no. 6, pp. 544-550, 2014.

[13] M. H. Gbetoh and M. Amyot, "Mercury, hydroquinone and clobetasol propionate in skin lightening products in West Africa and Canada," Environmental Research, vol. 150, pp. 403-410, 2016.

[14] A. M. Htet, E. E. Thin, M. M. Saw, and S. Win, "Chemical analysis of hydroquinone and retinoic acid contents in facial whitening creams," Asian Journal of Pharmaceutical Sciences, vol. 11, no. 1, pp. 89-90, 2016.

[15] C. Desiderio, L. Ossicini, and S. Fanali, "Analysis of hydroquinone and some of its ethers by using capillary electrochromatography," Journal of Chromatography A, vol. 887, no. 1-2, pp. 489-496, 2000.

[16] M. Buleandra, A. A. Rabinca, C. Mihailciuc et al., "Screenprinted Prussian Blue modified electrode for simultaneous detection of hydroquinone and catechol," Sensors and Actuators, B: Chemical, vol. 203, pp. 824-832, 2014.

[17] M. Aragó, C. Ariño, À. Dago, J. M. Díaz-Cruz, and M. Esteban, "Simultaneous determination of hydroquinone, catechol and resorcinol by voltammetry using graphene screen-printed electrodes and partial least squares calibration," Talanta, vol. 160, pp. 138-143, 2016.

[18] G. Xu, B. Li, and X. Luo, "Carbon nanotube doped poly(3,4ethylenedioxythiophene) for the electrocatalytic oxidation and detection of hydroquinone," Sensors and Actuators B: Chemical, vol. 176, pp. 69-74, 2013.

[19] J. Tashkhourian, M. Daneshi, F. Nami-Ana, M. Behbahani, and A. Bagheri, "Simultaneous determination of hydroquinone and catechol at gold nanoparticles mesoporous silica modified carbon paste electrode," Journal of Hazardous Materials, vol. 318, pp. 117-124, 2016.

[20] M. R. Siddiqui, Z. A. AlOthman, and N. Rahman, "Analytical techniques in pharmaceutical analysis: a review," Arabian Journal of Chemistry, 2013.

[21] P. O. Odumosu and T. O. Ekwe, "Identification and spectrophometric determination of hydroquinone levels in some cosmetic creams," African Journal of Pharmacy and Pharmacology, vol. 4, no. 5, pp. 231-234, 2010.

[22] T. E. Kipngetich, M. Hillary, and M. Shadrack, "UV-VIS analysis and determination of hydroquinone in body lotions and creams sold in retail outlets in Baraton, Kenya," Baraton Interdisplinary Research Journal, vol. 3, no. 1, pp. 23-28, 2013.

[23] P. L. García, M. I. R. M. Santoro, A. K. Singh, and E. R. M. Kedor-Hackmann, "Determination of optimum wavelength and derivative order in spectrophotometry for quantitation of hydroquinone in creams," Brazilian Journal of Pharmaceutical Sciences, vol. 43, no. 3, pp. 397-404, 2007.

[24] E. S. Elzanfaly, A. S. Saad, and A.-E. B. Abd-Elaleem, "Simultaneous determination of retinoic acid and hydroquinone in skin ointment using spectrophotometric technique (ratio difference 
method)," Saudi Pharmaceutical Journal, vol. 20, no. 3, pp. 249253, 2012.

[25] M. R. Elghobashy, L. I. Bebawy, R. F. Shokry, and S. S. Abbas, "Successive ratio subtraction coupled with constant multiplication spectrophotometric method for determination of hydroquinone in complex mixture with its degradation products, tretinoin and methyl paraben," Spectrochimica Acta Part A: Molecular and Biomolecular Spectroscopy, vol. 157, pp. 116-123, 2016.

[26] H. Chen, Z. Lin, H. Tang, T. Wu, and C. Tan, "Quantitative analysis of dihydroxybenzenes in complex water samples using excitation-emission matrix fluorescence spectroscopy and second-order calibration," Journal of Spectroscopy, vol. 2014, Article ID 412039, 7 pages, 2014.

[27] S. Uddin, A. Rauf, T. G. Kazi, H. I. Afridi, and G. Lutfullah, "Highly sensitive spectrometric method for determination of hydroquinone in skin lightening creams: application in cosmetics," International Journal of Cosmetic Science, vol. 33, no. 2, pp. 132-137, 2011.

[28] B. B. Qassim and H. S. Omaish, "Development of FIA system for the spectrophotometric determination of hydroquinone in pure material and pharmaceutical formulations," Journal of Chemical and Pharmaceutical Research, vol. 6, no. 3, pp. 1548-1559, 2014.

[29] A. F. Seliem and H. M. Khalil, "Sensitive spectrophotometric method for determination of hydroquinone in some common cosmetics in Najran region in K.S.A," Ultra Chemistry, vol. 9, no. 2, pp. 221-228, 2013.

[30] Y. Ni, Z. Xia, and S. Kokot, "A kinetic spectrophotometric method for simultaneous determination of phenol and its three derivatives with the aid of artificial neural network," Journal of Hazardous Materials, vol. 192, no. 2, pp. 722-729, 2011.

[31] C.-Y. Cheng, Y.-T. Chan, Y.-M. Tzou, K.-Y. Chen, and Y.-T. Liu, "Spectroscopic investigations of the oxidative polymerization of hydroquinone in the presence of hexavalent chromium," Journal of Spectroscopy, vol. 2016, Article ID 7958351, 8 pages, 2016.

[32] L. R. Goldfrank and N. E. Flomenbaum, "Toxic alcohols," in Goldfrank's Toxicologic Emergencies, L. R. Goldfrank, N. E. Flomenbaum, N. A. Lewin et al., Eds., pp. 1049-1060, Appleton and Lange, Stamford, Conn, USA, 6th edition, 1998.

[33] H. Borsook, H. W. Davenport, C. E. P. Jeffreys, and R. C. Warner, "The oxidation of ascorbic acid and its reduction in vitro and in vivo," The Journal of Biological Chemistry, vol. 117, no. 1, pp. 237279, 1937.

[34] A. Shrivastava and V. Gupta, "Methods for the determination of limit of detection and limit of quantitation of the analytical methods," Chronicles of Young Scientists, vol. 2, no. 1, pp. 21-25, 2011.

[35] G. Latimer, Official Methods of Analysis of AOAC International, AOAC, Gaithersburg, Md, USA, 2012.

[36] D. Bandyopadhyay, "Topical treatment of melasma," Indian Journal of Dermatology, vol. 54, no. 4, pp. 303-309, 2009.

[37] C. B. Lynde, J. N. Kraft, and C. W. Lynde, "Topical treatments for melasma and postinflammatory hyperpigmentation," Skin Therapy Letter, vol. 11, no. 9, pp. 1-6, 2006.

[38] A. J. Stratigos and A. D. Katsambas, "Optimal management of recalcitrant disorders of hyperpigmentation in dark-skinned patients," American Journal of Clinical Dermatology, vol. 5, no. 3, pp. 161-168, 2004.

[39] S. Bruce and J. Watson, "Evaluation of a prescription strength $4 \%$ hydroquinone $10 \%$ L-ascorbic acid treatment system for normal to oily skin," Journal of Drugs in Dermatology, vol. 10, no. 12, pp. 1455-1461, 2011.
[40] J. T. E. Lim, “Treatment of melasma using kojic acid in a gel containing hydroquinone and glycolic acid," Dermatologic Surgery, vol. 25, no. 4, pp. 282-284, 1999.

[41] R. C. Monteiro, B. N. Kishore, R. M. Bhat, D. Sukumar, J. Martis, and H. K. Ganesh, "A comparative study of the efficacy of $4 \%$ hydroquinone vs $0.75 \%$ Kojic acid cream in the treatment of facial melasma," Indian Journal of Dermatology, vol. 58, no. 2, p. 157, 2013.

[42] http://www.amazon.com/Procelain-Skin-Whitening-HydroquinoneHyperpigmentation/dp/B009JJA49U. 

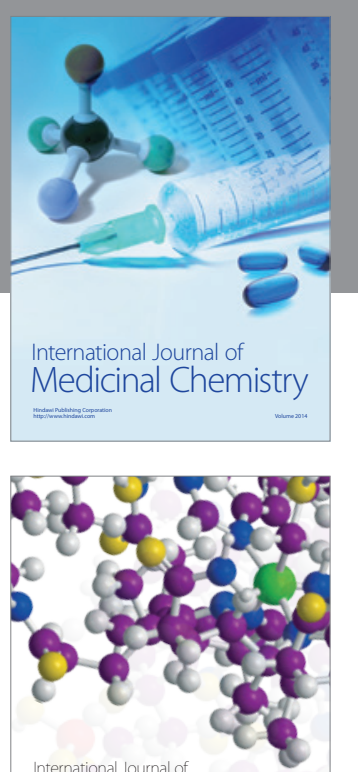

Carbohydrate Chemistry

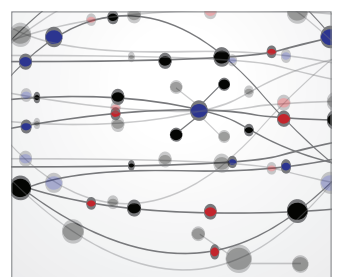

The Scientific World Journal
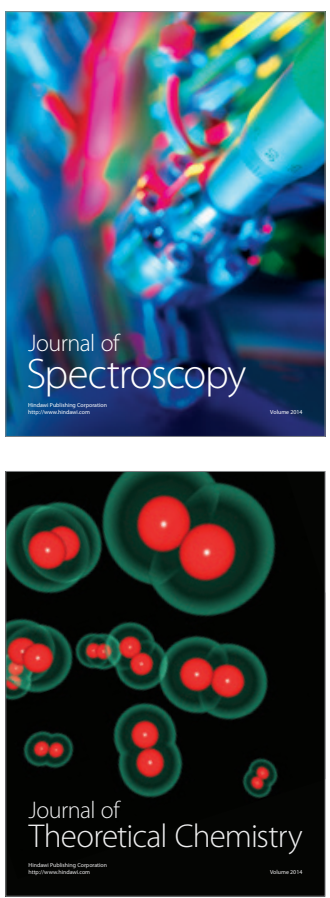
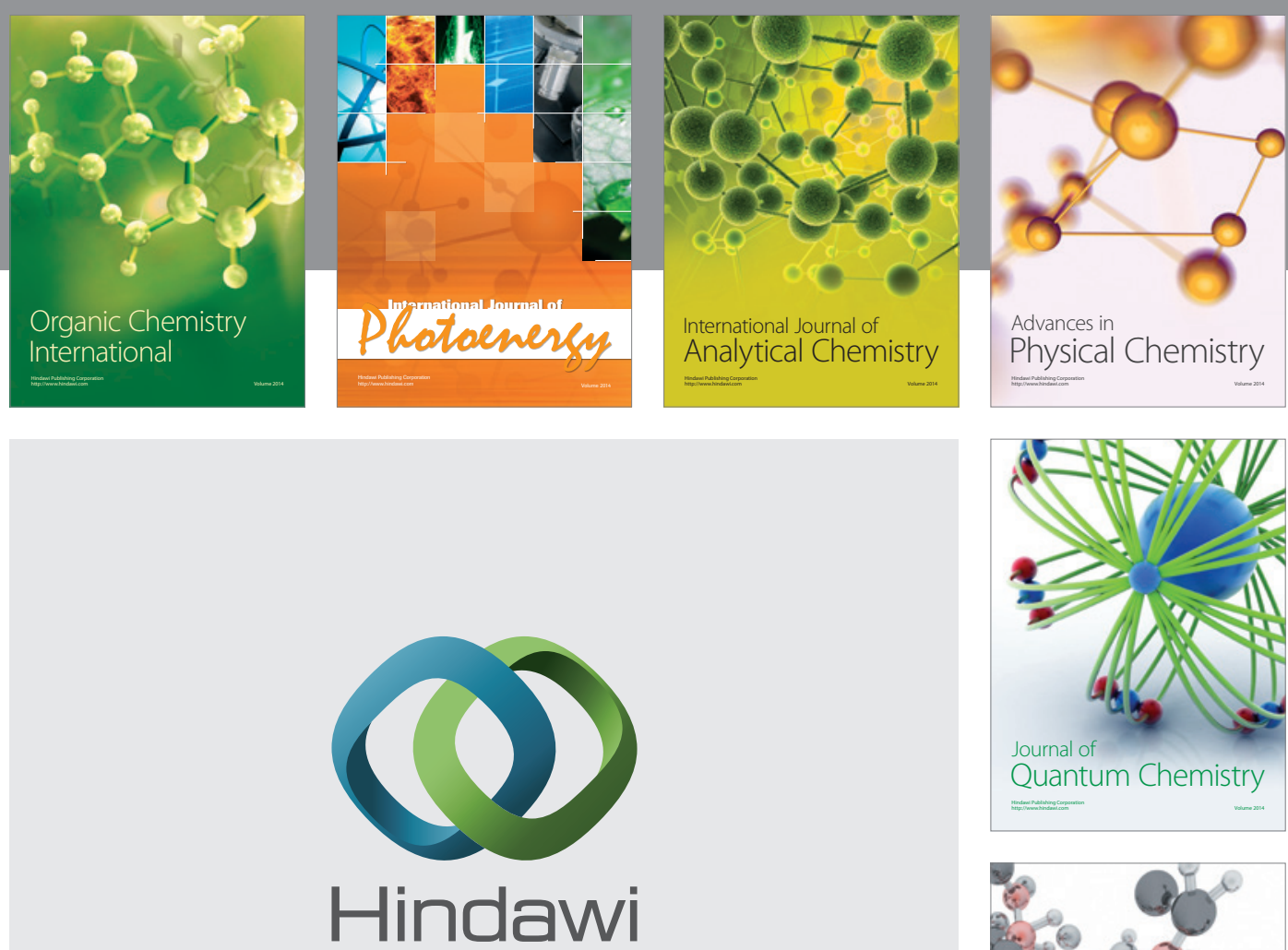

Submit your manuscripts at

https://www.hindawi.com

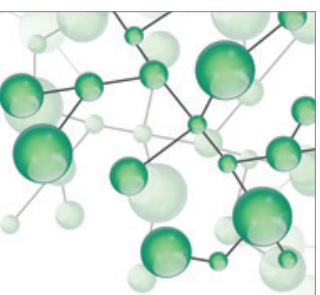

International Journal of

Inorganic Chemistry
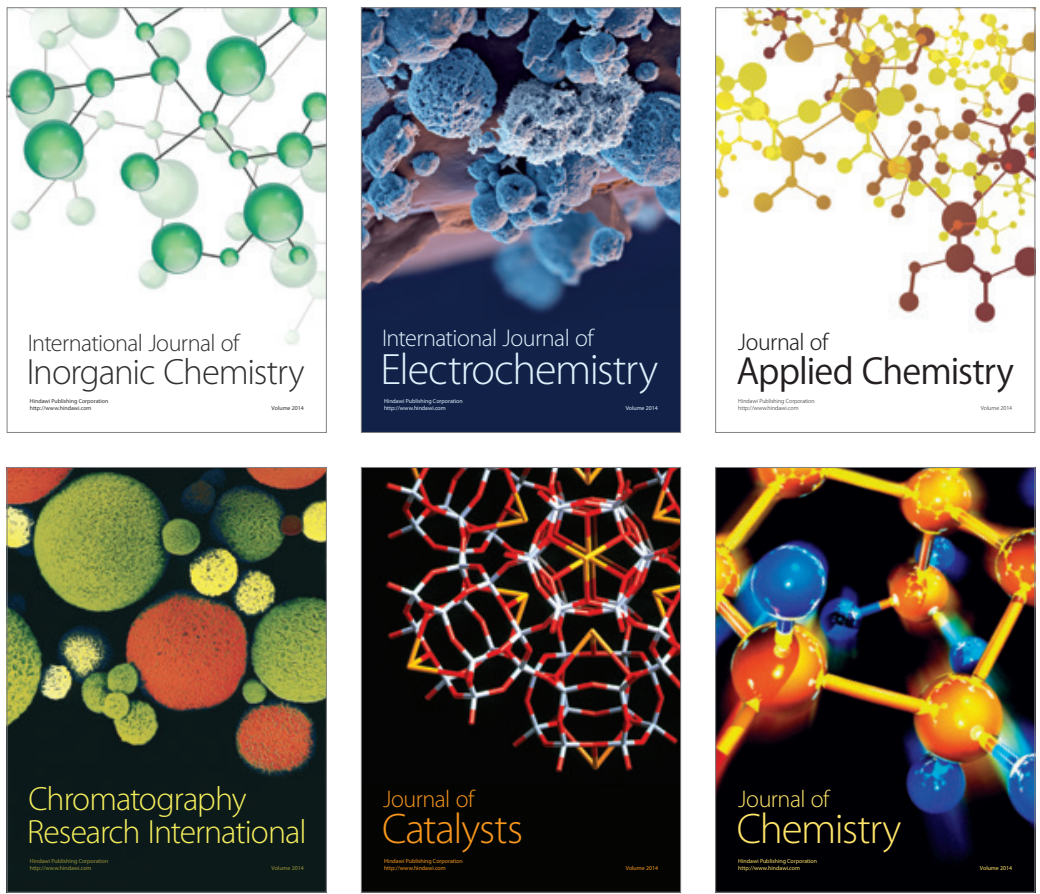

Journal of

Applied Chemistry
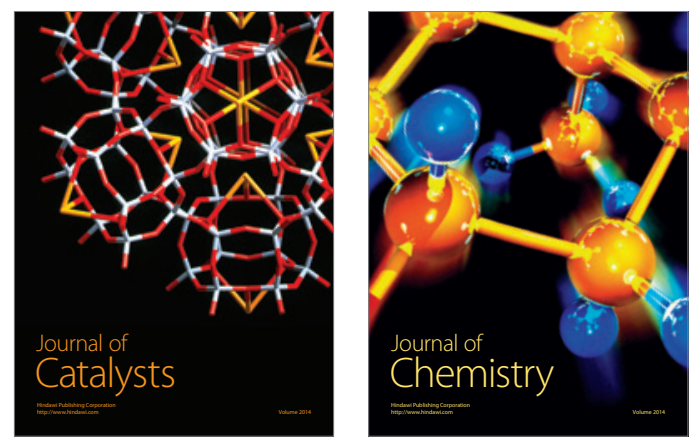
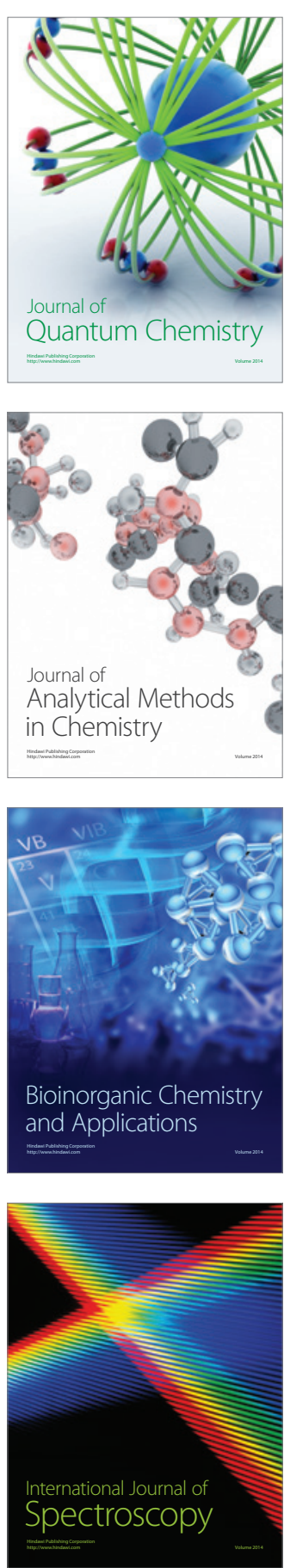